\title{
Sobre el concepto de legitimidad: Oposición entre una visión optimista y pesimista
}

\author{
Henry Forero-Medina ${ }^{1}$
}

forero_henry@yahoo.com.mx

\section{Cómo citar este artículo:}

Forero-Medina, H. (2018). Sobre el concepto de legitimidad: posición entre una visión optimista y pesimista. TransPasando Fronteras, (12).

1 Doctorando en Ciencias Sociales y Doctorando en Filosofía por la UBA, Magíster en Semiótica y en Filosofía (C. Profesor de Filosofía Política y Social de la USAL-San Miguel, Docente (auxiliar) de Sociología del Derecho y la Dominación en Derecho UBA y de Maestrías y Doctorados en la USAL, UBA, UNTREF y la UIS. Miembro del Programa Internacional PIDESONE y del Equipo de Estudios DESCOLONIA: Justicia y Sociedad desde el Sur, del Departamento de Ciencias Sociales de la Facultad de Derecho de la Universidad de Buenos Aires-UBA y el Doctorado en Filosofía de la USAL. Miembro del Grupo de Investigación en Ética, Antropología Filosófica y Filosofía Intercultural, del Instituto de Filosofía de la Facultad de Filosofía y Letras de la Universidad de Buenos Aires-UBA. 
No es legítimo ningún gobierno que no trate con igual consideración la suerte de todos los ciudadanos a los que gobierna y que exige lealtad. La igualdad de consideración es la virtud soberana de la comunidad política. Y cuando la riqueza de una nación está disribuida muy desigualmente (...) cabe sospechar de su igualdad de consideración.

Ronald Dworkin. Virtud Soberana.

\section{Resumen}

La capacidad funcional del sistema económico para asumir el papel de integrador autoreflexivo en la sociedad, describe el modelo de significado dinámico-binario que hace oscilar entre el optimismo y el pesimismo la lógica de la selectividad del modelo de racionalidad dominante (Beriain, 1996), en el que se configura un marco ilusorio de intervención orgánica-política que a la vez que incrementa su rendimiento, injerencia y poder decisorio, impide o invisibiliza la puesta en marcha de alternativas fácticas provenientes de la vida social, donde lo nuevo o alternativo deviene en parte integral de lo mismo. Tal competencia se consolida con la difusión progresiva de escenarios controlados de intervención colectiva, comunitaria o social en los que sofisticadas estrategias de recepción imaginaria canalizan y bloquean las demandas de bienes públicos mínimos al reducirlas a participación democrática exponencial o a simples mecanismos de inclusión simulada. 
De aquella parte se obtiene el elemento fundante que sostiene al sistema político y del que depende el jurídico. Su rastro, no obstante, apunta hacia el mercado financiero y de servicios, el consumo y el capital transnacional. Este proceso de transformación se entiende como de legitimación aparente homogeneizante, y son sus etapas las que modifican el paradigma del Estado nacional centralizado (autónomo).

\section{i}

El movimiento pesimista señala el gran poder facultativo de los agentes externos sobre los ordenamientos jurídicos nacionales y sus eficaces propiedades legislativas -reguladoras- y vinculatorias (Gunther, 2003), que articulados con los medios de comunicación adscritos o dependientes a su campo parecen disolver la hegemónica unidad del sistema jurídico.

El nuevo esquema reconfigura, además de la coherencia representativa y el significado de la delegación, la fuerza de la confianza y la convicción. Se trata de la constitución de una autoridad relativa a sí misma, que determina el peso de intereses, procedimientos, accesos, responsabilidades, decisiones y consecuencias (Gunther, 2003: 227), con repercusiones en las formas de saber, hacer y usar un derecho, cada vez más exclusivo de firmas de abogados que se encargan de diseñar -a solicitud- constituciones, convenciones y fuentes interpretativas, para optimizar y fijar la distancia cognitiva y aspectual -espacial y temporal- entre las ciudadanías económicas agentes frente a las destinatarias pacientes.

El curso de la acción busca fortalecer la expansión de las estabilidades posicionales en coexistencia con las promesas incumpli- 
das (Beriain, 1996: 14-15). Maximizar los condicionamientos e intensificar las expectativas de necesidad perfilan el ejercicio incesante y simultáneo de despliegue diferenciador como reacción ante el incremento de contingencia (Beriain, 1996: 20-22). En efecto, el Estado pretende hacer frente a las consecuencias colaterales latentes desde el rol ambivalente de mediador justificativo de rutinas alienantes (Gunther, 2003: 240) y negociador de vínculos procedimentales, que en todo caso lo eximen del intercambio y las interacciones normativas-discursivas propias del código sociocultural democrático.

Se establece el recorrido de la transacción concurrente -concordante- que a partir de las implicaciones que van de lo externo a lo interno reestructuran la praxis jurídica en categorías expansivas y escalonadas, que en suma, dan forma a la interlegalidad (Gunther, 2003: 245) adaptativa o anticipatoria, que neutraliza la potencialidad actualizante de la igualdad material y la legitimidad sustancial. Se subordina la complementariedad moral política a la libre circulación estratégica del cálculo, de donde emerge un anclaje recíproco y simbólico que operativiza el evento imperceptible de los valores en juego. Al institucionalizar el desgaste ordenativo y desfigurar -informar- el impacto sobre la vida cotidiana que prolonga la dialéctica entre intensionalidad versus extensionalidad, se obtiene el moldeo de los mecanismos de la autorreferencialidad, que dividen y emplazan dentro de la dimensión existencial, la magnitud de la confusión e introducen y encadenan nuevos parámetros de riesgo (Beriain, 1996: 34-37).

La pretendida formalización multiplica la producción de exclusión, distinción, diferencia, marginalidad y desigualdad a través de procesos de expropiación y pérdida del contexto ontológico y sus representaciones éticas y políticas, que reprimen la pertenencia plena 
a la ciudadanía democrática, sometida en tanto a una lógica y a una visión de mundo dominante, que convertidas en conquistas se ratifican en acervos reconocidos e inscritos como referentes cognitivos (Bourdieu, 2002), que facultan instaurar la soberanía del ethos de la resignación, el servilismo y la obediencia (Marcuse, 1968: 35-36).

Las personas privadas construyen sus estilos de vida con base en las reglas del trabajo que a su vez, dictan los perímetros de realización efectiva mediante distractores y sustitutos de satisfacción (Marcuse, 1968: 114-115), pertenecientes al complejo entramado de la realidad compartida y apropiada que ha hecho de fracciones de control y de poder como la policía y la justicia los campos idóneos para profundizar en la necesaria separación (Foucault, 1994: 28-29), que exige el isomorfismo vinculante de la fuerza del continuum racional imperante, conforme a particulares maneras de entender la moral, la justicia y lo propio (Kennedy, 2005: 104-105), cuyo fin es mantener las estructuras coordinadas y atentas a los parámetros instrumentales comunicativos como el dinero, el poder y la verdad, exentos de contenido normativo y con resultados cosificadores.

La reunión de dichos componentes privilegia la institucionalización en menoscabo de la integridad -constitutiva- de las formas de vida en busca de regularizar una subjetividad colectiva periférica y evitar elevar el sentido performativo en autoría pública activa.

Se sustituye la legitimidad discursiva y la igualdad política por una razón orientada por expectativas subjetivas de beneficio (Beriain, 1996: 125), con el progresivo debilitamiento de los sucesos de ensamble factual-discursivo -enunciados judiciales- y de la deliberación ética como soportes de validez sistémica y eficacia social. 


\section{ii}

El movimiento optimista alega, por su parte, el poder sustantivo y garante de los tribunales constitucionales sobre la praxis hegemónica reguladora y sus efectos intersistémicos, según la tesis que erige a la constitución como reguladora, por limitar las acciones de los poderes públicos, y como programa, al señalar una respectiva dirección axiológica (Uprimny \& Rodríguez, 2004: 2-3), es decir, como referente estabilizador, tanto del orden social como de la potencial potestad verificativa conducente a la eficacia, que encuentra en el reconocimiento la inestable conexión entre la expectativa funcional observable y su adecuación a la expectativa normativa latente.

La constituciones en la modernidad fluctúan entre la actualidad normativa y la potencialidad valorativa, a saber, entre lo cierto pero inestable y lo incierto pero estable, y ese rol concede, administra y justifica el acople entre los derechos liberales con los sociales, como táctica contingente de asignación de apertura y acto comunicativo entre política, economía y derecho, que al provenir de una competencia instrumental se traduce en una reducción de complejidad que identifica lo próximo con el mismo entorno que lo habilita en diversificante consecutivo de derechos.

Su sentido se mantiene neutral ante la irrupción de cualquier variante económica, y es su carácter autorregulador el que ejerce sobre los intereses y beneficios una evaluación de lo razonable o leve del objetivo que se persigue, su admisible integralidad, y su praxis potencialmente adecuada, con la sucesiva adscripción del destinador deóntico -juez- a la observación del juego de expectativas sociales cambiantes, a través de sus manifestaciones discursivas imperativas y vinculantes (Uprimny \& Rodríguez, 2004: 8). La pretendida formulación de límites ocurre en el terreno simbólico de la distinción teórica entre principios y reglas, que para la efectivi- 
dad de la comunicación jurídica contienen una estructura lógica distinta, ya que mientras las reglas siguen la forma de mandato definitivo, los principios significan algo deseable - o no- sin especificar el medio de ser adquirido (Uprimny \& Rodríguez, 2004: 9).

La función de protección de las expectativas - de cuidado del capital social- se debe al rol de neutralizador imparcial que asume el juez, en un primer lugar, como preservador defensivo y progresivo de la positividad, y en segundo, como representante de su estatus. Esta distinción se funda en la idea de que las decisiones judiciales son acontecimientos repetitivos -reiterativos- de su especial sentido reflexivo de corrección -autocorrección-.

Se renueva la cualificación performativa de la fuerza de la justicia, que pospone la muerte del mundo en cada caso, para responder así, en términos procedimentales, a las demandas hechas por el entorno, por medio de la argumentación que acopla las estructuras informativas que habilita la inclusión de nuevos elementos y dispone la posibilidad de reaccionar ante requerimientos imprevistos como fenómenos jurídicos. Autocentración que significa la obligación decisoria de comprometer el avance de las demandas y la comunicación acerca de ellas (Luhmann, 2002: 384).

Consistencia que configura la funcionalidad del tribunal y sus respuestas operativas a las expectativas normativas. Define el juez lo jurídicamente posible, concebido como estabilidad procedimental selectiva que relaciona las esferas de exigencia y las adapta o traduce a su lógica de validez, en detrimento de la contingencia, cuyo elemento definitorio es la atribución de fuerza vinculante de las decisiones de compatibilidad constitucional excluyente de sobrecargas extensionales - exógenas-, que destaca la cuestión básica, entendida como legitimidad o respuesta esperada, con fundamento en los presupuestos consensuales previos o principios condicionales. 


\section{Colofón}

Indagar por las fuentes de legitimidad del sistema jurídico moderno exige una revisión de los entornos diferenciados de acuerdo a su función y cada una de las prestaciones sistémicas. La unidad del sistema jurídico se puede observar o bien desde determinados condicionantes, a partir de los actos comunicativos de los códigos específicos y su carácter binario, o frente a las reacciones de la saturación de complejidad y sus respuestas procedimentales racionalizadas.

Los elementos económicos vistos en sus roles y estrategias prefiguran unas competencias volitivas y pragmáticas particulares que mediante su observación denotan funcionalidades complejas orientadas a intencionalidades justificativas de sus propias lógicas de interpretación y praxis.

El sistema jurídico utiliza conjunciones normativas y cognitivas que refuerzan el carácter vinculante y prioritario del sentido de su intervención y supremacía autorreferencial. Dentro, en su centro, se encuentra el mecanismo que equilibra sus oscilaciones mediante el principio de corrección que lo faculta para ser dador de justicia y regulador de lo periférico - a sí mismo-.

Ambas experiencias perfilan dos dimensiones cognitivas con sus respectivas expectativas, que se entrecruzan y se asumen para observarse y reclamar vigencia, no obstante ser relativos y realizativos, y tener pretensiones de sistema, es decir, de producir y reproducir un sentido anclado en el entendimiento de sus semánticas; recorrido que engloba el propósito representativo y descriptivo de esta reflexión. 


\section{Referencias Bibliográficas}

Beriain, J. (1996). Las consecuencias perversas de la modernidad. Barcelona: Anthropos.

Bourdieu, P. (2002). Elementos para una sociología del campo jurídico. En La fuerza del derecho (págs. 161-204). Bogotá: Ediciones Uniandes, Instituto Pensar, Siglo del Hombre Editores.

Foucault, M. (1994). Estrategias de poder. Barcelona: Paidós.

Gunther, K. (2003). Pluralismo jurídico y Código Universal de la Legalidad: la globalización como problema de la Teoría del Derecho. Anuario de Derechos Humanos, Nueva época, Volumen 4, 225.

Kennedy, D. (2005). Libertad y restricción en la decisión judicial. El debate con la teoría crítica del derecho. Bogotá: Siglo del Hombre Editores.

Luhmann, N. (2002). El derecho de la sociedad. México: Universidad Iberoamericana.

Marcuse, H. (1968). Cultura y sociedad. Buenos Aires: Editorial Sur S.A.

Uprimny, R., \& Rodríguez, C. (Septiembre de 2004). Constitución y modelo económico en Colombia: hacia una discusión productiva entre economía y derecho. Ponencia presentada en el seminario sobre el tema organizado por el Ministerio de Hacienda. Bogotá. 


\section{Bibliografía adicional utilizada y recomendada}

ADORNO, Theodor: "Crítica, Cultura y Sociedad" Editorial Ariel S.A. Barcelona-España. 1969.

BUCHANAN, James M. "Ética y Progreso Económico". Editorial Ariel S.A. Barcelona 1996.

DE ZUBIRIA, Sergio, "Filosofía de nuestro ethos cultural", Revista de Estudios Sociales Número 01. Agosto 1998.

DíAZ, Elías, "Ética contra política", Editorial Distribuciones Fontamara S.A., México, 1998.

FARRELL, Diego Martín. Utilitarismo, liberalismo y democracia. Ediciones Fontamara S.A. Biblioteca de ética, Filosofía del derecho y política. México. 1997.

GIL, Numas Armando. (Compilador), Filosofía del Derecho y Filosofía Social (Memorias Tercer Congreso Nacional), Bogotá D.C.: Grupo Editorial Ibáñez, 2006. Justicia Juris, ISSN 16928571, Vol. 6. N 11. Abril - Septiembre 2009 Pág. 119-138.

MEJÍA QUINTANA, Oscar. "El origen constituyente de la crisis política en Colombia" en Ann Mason \& Luis Javier Orjuela (eds), La Crisis Política Colombiana, Bogotá, D.C.: Uniandes (Departamento de Ciencia Política), 2003.

MEJÍA QUINTANA, Oscar. "Elementos para una reconstrucción del estatuto epistemológico de la filosofía del derecho" en Humanitas (No. 33), Nuevo León: Centro de Estudios Humanísticos (Universidad Autónoma de Nuevo León), 2006. 
MEJÍA QUINTANA, Oscar, "La Norma Básica como Problema lusfi losófi co. Tensiones y aporías del positivismo y las apuestas pospositivistas de superación" en Numas Gil (compilador), Filosofía del Derecho y Filosofía Social (Memorias Tercer Congreso Nacional), Bogotá D.C.: Grupo Editorial Ibáñez, 2006.

SCHMITT, Carl, "Legalidad y Legitimidad", Trad. José Díaz García, Madrid: Aguilar, 1971. 